\title{
Documentation of Traditional Knowledge Associated with Medicinal Animals in West Gojjam Zone of Amhara Region, Ethiopia
}

\author{
Manaye Misganaw ${ }^{*}$, Nigusie Seboka, Abiyesilassie Mulatu \\ Ethiopian Biodiversity Institute, Genetic Resource Access and Benefit Sharing Directorate, Addis Ababa, Ethiopia \\ Email address: \\ manaye9@gmail.com (M. Misganaw),nigussie88@gmail.com (N. Seboka), abiyselassiemulatu@gmail.com (A. Mulatu) \\ ${ }^{*}$ Corresponding author
}

\section{To cite this article:}

Manaye Misganaw, Nigusie Seboka, Abiyesilassie Mulatu. Documentation of Traditional Knowledge Associated with Medicinal Animals in West Gojjam Zone of Amhara Region, Ethiopia. American Journal of Life Sciences. Vol. 9, No. 3, 2021, pp. 45-54.

doi: 10.11648/j.ajls.20210903.12

Received: March 15, 2021; Accepted: May 21, 2021; Published: May 27, 2021

\begin{abstract}
Ethnozoology and Zootherapeutic research is very limited and little attention has been given in Ethiopia. The study was designed to investigate and document traditional knowledge associated with medicinal animals in West Gojjam Zone of Javitenan, North Achefer, and Bahir Dar Zuria districts. Ethnozoological data were collected using structured questionnaires and use value (UV), informant consensus factor (ICF), fidelity level (FL), preferential ranking, and paired comparison were analyzed. A total of 26 animal species were identified and recorded as a source of medicine to treat 33 types of ailments. Animal-derived medicines of Bos indicus, Trigona spp., and Apis mellifera were frequently reported species to treat various ailments. Bos indicus, Trigona spp., Apis mellifera, Hyaenidae carnivora, and Labeobarbus spp. were the most frequent usevalue reports $(84 \%, 52 \%, 43 \%, 37 \% 36 \%)$ respectively. Informants reported 25 animal parts to treat ailments. Honey and meat took the highest frequency use report followed by purified butter, Milk, Liver, fatty meat, and Cheese stored more than 7 years were described with an average ICF value of $69 \%$. A maximum degree of consensus was developed for the remedy of the evil eye ( $88 \%)$ followed by dry cough, swelling, and hepatitis $82 \%$ each. Use of animal-derived medicine from Liotrigona spp. used to relive dry-cough tend to have the highest FL (80\%); followed by Labeobarbus spp. for swelling (33\%) and Trigona $s p p$. for dry-cough (30\%). Paired comparisons revealed that purified butter $\geq 2$ years, Cheese $\geq 7$ years, honey of Liotrigona spp. (YetinignTazma), and honey of Trigona spp. (Tazma) was the most popular and efficacious animal-derived medicines to cure malaria and ranked $1^{\text {st }}, 2^{\text {nd }}, 3^{\text {rd }}$, and $4^{\text {th }}$, respectively. Results of this study recorded the most popular animal-derived medicine to cure various ailments. Thus, the government must strengthen traditional healers with training, club formation, material and financial support, and improve means of protecting their intellectual property rights. Moreover, chemists and pharmacists should undergo a detailed study to identify which chemical constituent of animal and animal products is responsible for the respective treatment of ailments in the study area.
\end{abstract}

Keywords: Informant Consensus, Medicinal Animals, Traditional Knowledge, Use Values

\section{Introduction}

Traditional Medicine has been practiced for several thousand years in different parts of the world particularly where large ethnic communities live in. Currently, more than $80 \%$ of the world population uses traditional medicine either on its own or as a complementary medicine [1]. More than $80 \%$ of the population in Sub-Saharan Africa relies on traditional medicines and Traditional Health Practitioners
(THPs) as the primary source of health care [2]. Like in many other developing countries, more than $70 \%$ of the human and $90 \%$ of the livestock population primarily depend on traditional medicine in Ethiopia [3].

The World Health Organization (WHO) defined traditional medicine (TM) as the total of all knowledge and practices, whether explicable or not, used in diagnosis, prevention, and elimination of physical, mental, or social imbalance and relying exclusively on practical experiences and observations 
handed from generation to generation, whether verbally or in writing [4]. The term TM covers traditional healers and their use of plant materials, animal origins, and inorganic mineral substances for health care in the context of social, cultural, and religious backgrounds [5]. The dynamic relationship between human culture or societies and animal resources in their environment can be studied in the field of ethnozoology [6]. Zootherapy is an important component of ethnozoology, involves the healing of human ailments by using therapeutic based on medicine obtained or ultimately derived from different animals [7].

The use of animal parts for the treatment of ailments affecting both humans and livestock has a long and rich history [8]. Wild and domestic animals and their by-products such as hooves, skins, bones, feathers, and tusks were important ingredients in the preparation of curative, protective, and preventive measures in various cultures [9, $10,8]$. There is varied and richer utilization of animals for illnesses in Latin America and Africa with a long period of traditional practices of animal remedies for all kinds of ailments [11]. Whole, parts or products of animal species such as scales of the tree pangolin species are used for the treatment of a wide range of human ailments in Ghana [1].

In Ethiopia, like in the rest of the world, research on ethnozoology is very limited, and only a little attention has been given to zootherapeutic research. As Alves noted that though medicinal animals are widely used in different countries for health care, it is little researched when compared to medicinal plants [12]. Only some researchers like Gelahun Abate tried to list around 23 animals used for the treatments of human diseases in Ethiopia [13]. As Gidey Yirga et al. reported the use of different parts and products of 16 species of medicinal animals such as bile, milk, blood, pancreas, urine, hair, and fecal matter to treat 18 different human ailments from Kunama in the Kafta-Humera district [14]. As Mezgebu Belay reported the use of various vertebrate and invertebrate, wild and domestic, taboo and edible animals in various forms such as meat, urine, feces, bone, skin, blood, fat, honey, milk, butter, bile, egg, etc. to treat various kinds of human ailments such as TB, rabies, impotence (sexual), asthma, snake biting, pellagra, evil eye, etc. and external pathologies like wounds and skin diseases from Gendewuha and Kumeraaftit people of Metema district [15]. Moreover, a total of 21 animal species were recorded to treat 46 different types of ailments in the Amaro district of Southern Nations and Nationalities People Regional State of Ethiopia [16].

The traditional knowledge of traditional healing practices using animals is now disappearing very rapidly due to modernization [17]. This loss of traditional knowledge has an impact on the development of modern medicine. It is important to document the traditional knowledge of human communities since the majority of such communities are losing their socio-economic and cultural characteristics [18]. Traditional healers in Ethiopia hold their indigenous knowledge in secret and little information has been recorded by few authors [19]. Therefore, the current paper reports the result of a study of the traditional knowledge associated with medicinal animals in West Gojjam Zone of Amhara Region, Ethiopia. The investigation and documentation of TK in medicinal animals of the area is very valuable in the development of pharmaceutical compounds for bioprospecting, and also very helpful in making strategies for sustainable utilization of natural resources and conservation of biodiversity. The objective of this study was to investigate and document traditional knowledge associated with medicinal animals and medicinal animals used by traditional healers in West Gojjam Zone.

\section{Materials and Methods}

\subsection{Description of the Study Area}

\section{i. Location}

The study was conducted in the West Gojjam zone, North West of Ethiopia particularly in Javitenan, North Achefer, and Bahir Dar Zuria districts in which practice, distribution, and use of medicinal plants and animals are high. West Gojjam zone is one of the 10 zones in the Amhara Region and lies between $36^{\circ} 30^{\prime}$ to $37^{\circ} 5^{\prime}$ ' Longitudes East and $10^{\circ} 16^{\prime}$ to $11^{\circ} 54^{\prime}$ Latitudes North [20]. The total population is estimated as 2,106,596 and more than $91 \%$ of the people lived in rural areas [21]. Agriculture is the main source of livelihood for the community. Administratively, the West Gojjam zone is divided into 13 rural districts and 5 town administrations [22]. The total land area of the West Gojjam zone is $13,280 \mathrm{~km}^{2}$. Its elevation varies from 1500 to 3500 m.a.s.l. Most of the districts (75\%) in the zone have an ambient temperature ranging from $15-20^{\circ} \mathrm{C}$ and the remaining has $20-27^{\circ} \mathrm{C}$ [23].

ii. Population

The study areas, namely North Achefer, Bahir Dar Zuria, and Jabitenan districts, are among three of the 14 districts found in the West Gojam zone. North Achefer is bordered in the North by Lake Tana; in the South by South Achefer; in the West by the North Gondar zone; in the East by Bahir Dar Zuria; and in the Southeast by Mecha. According to the Central Statistical Agency of Ethiopia, this district has a total population of 189,716 [21]. The majority of the inhabitants $(99.05 \%)$ practiced Ethiopian Orthodox Christianity religion. Bahir Dar Zuria borders in the South by Yilmana Densa; in the Southwest by Mecha; in the Northwest by the Lesser Abay River which separates it from North Achefer; in the North by Lake Tana (On the shores of Lake Tana situates the city and special zone of Bahir Dar); and in the East by the Abay River which separates it from the South Gondar Zone. Based on the Central Statistical Agency of Ethiopia, this district has a total estimated population of 182,730 [21]. Jabitenan borders in the Southeast by Dembecha; in the West by Bure; in the Northwest by Sekela; in the North by Quarit; and in the East by Dega Damot districts. According to Central Statistical Agency of Ethiopia, the district has a total estimated population of 179,342 [21]. The three districts 
have long been inhabited by people who have an age-old tradition of using medicinal animals and plants to treat

human and livestock ailments.

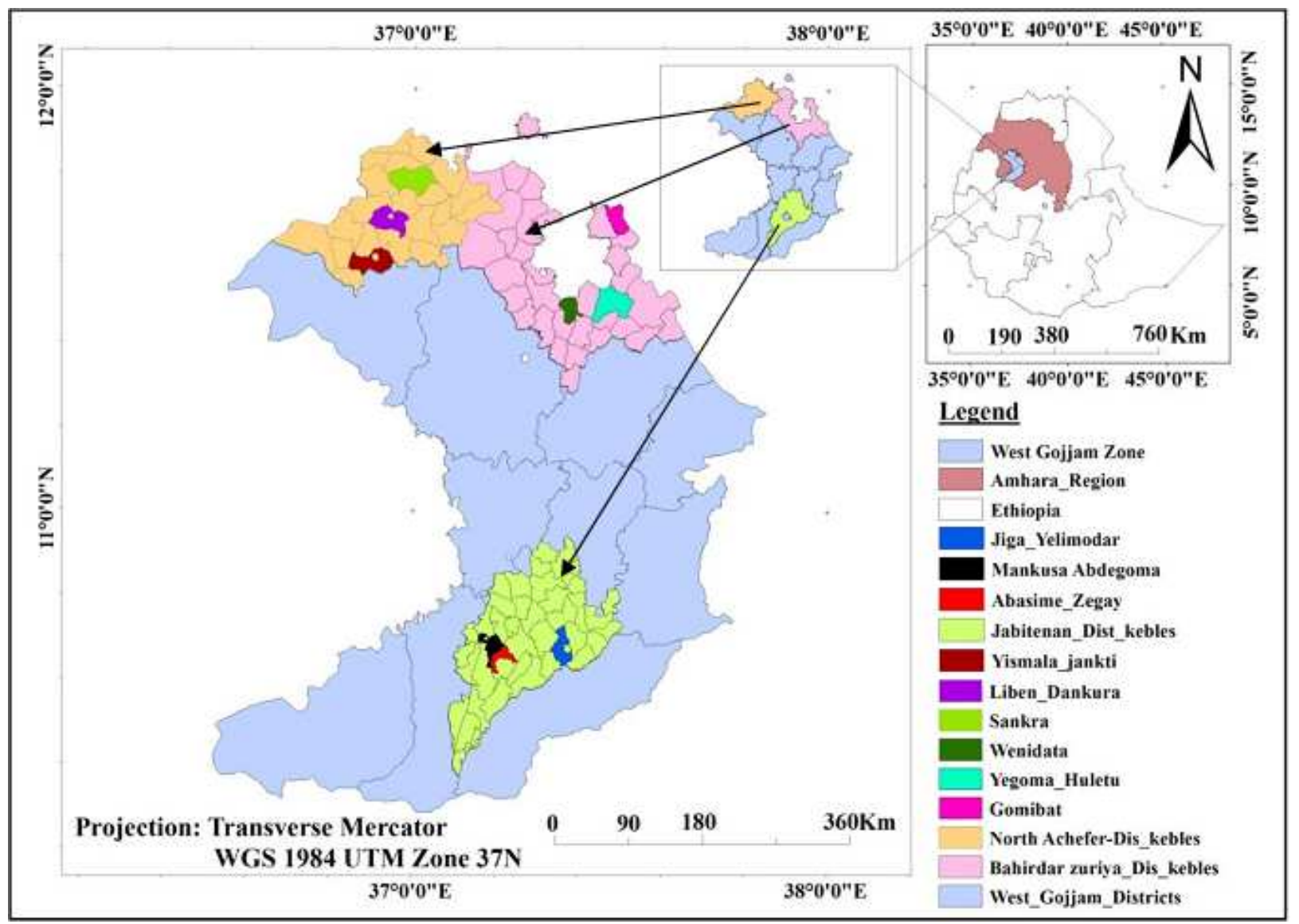

Figure 1. Map of the study area.

\subsection{Data Collection Method}

The study zone, districts, and Kebeles were selected purposively based on the availability of traditional medicine practitioners following the information obtained from literature and information from zonal and district health bureaus of the Amhara Region. Three districts from a zone and three representative Kebeles from each district, namely: Jiga-Yelimodar, Mankusa-Abdegoma, and Abasime-Zegay from Javitenan; Yismala-Jankit, Liben-Dankura and Sankra from North Achefer; and Wenidata, Yegoma-Huletu, and Gomibat from Bahir Dar Zuria; were selected. Then, on average, 9 respondents (traditional medicine practitioners) and 2 key informants (traditional healers) were selected from each Kebele. The informants were selected based on their experience, recognition as a traditional healer, knowledge of healing practice, and age. Ethno-zoological data were collected using semi-structured questionnaires. The questions were prepared in English, translated into a local language, and administered through interviews. For each ethnozoological medicine, the target groups were asked to explain its therapies, preparation methods, diseases claimed to be treated, parts of animals used, routes of administration, and the local name of the species. The information regarding the use of a particular animal for a specific disease was treated as one user report.

\subsection{Data Analysis}

The ethno-zoological data were analyzed using SPSS version 21 and a Microsoft Excel spreadsheet was used to analyze use-value, informant consensus factor, fidelity level, preferential ranking, and paired comparison.

A. Use value $(U V)$ : was calculated for an individual animal to give a quantitative measure of its relative importance to the informant objective.

$\mathrm{UVs}=\sum_{\mathrm{i}} \mathrm{UV}_{\mathrm{is}} / \mathrm{n}$; where: $\mathrm{UV}=$ the use value of a species $\mathrm{UVi}=$ number of use reports cited by the informants for that particular species

$\mathrm{N}=$ total number of respondents interviewed

B. Informant consensus factor (ICF): was calculated to determine the homogeneity of the informant for a particular animal to treat a particular ailment.

$\mathrm{ICF}=\left(\mathrm{N}_{\mathrm{ur}}-\mathrm{N}_{\mathrm{t}}\right) /\left(\mathrm{N}_{\mathrm{ur}}-1\right)$; where:

$\mathrm{N}_{\mathrm{ur}}=$ total number of use reports for a particular illness category

$\mathrm{N}_{\mathrm{t}}=$ total number of species used for this illness category

C. Fidelity level (FL): was calculated to express the preference of a species to other species in the 
management of a particular ailment

$\mathrm{FL}=\left(\mathrm{I}_{\mathrm{p}} / \mathrm{I}_{\mathrm{u}}\right) * 100$; where:

Ip $=$ the number of informants stating the use of a species for a particular ailment category

$\mathrm{Iu}=$ number of informants stating the use of that species for any sort of ailment category

D.Preferential ranking: was made to rank the popular medicinal animals according to their healing capacity of certain ailments. The popular medicinal animal was ranked by the selected informants. Informants were oriented and asked to mark the highest value for most preferred and 1 for the least preferred medicinal animal to treat malaria, rabies, hepatitis, dry cough, epilepsy, arthritis, and asthma. Then summed up values, ranked and illustrated in tables.

E. Paired comparison: was used to evaluate the degree of preference of the selected medicinal animals reported from the study area to treat a certain disease. A list of pairs of selected items with all possible combinations was made, and the sequence of the pairs and the order within each pair was randomized and presented to selected informants and their responses were recorded; and total scores were summed up using the $n(n-1) / 2$; where $\mathrm{n}=$ the number of medicinal animals being compared. The data were summarized using descriptive statistics and presented by percentages, frequency distribution, tables, charts, and graphs.

\section{Results and Discussion}

\subsection{Demography}

A total of 83 informants $85.9 \%$ males and $14.1 \%$ females and

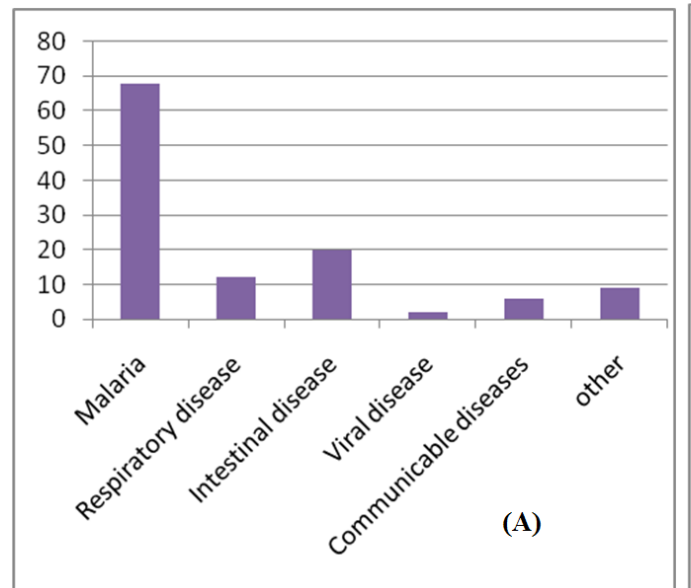

18 key informants were interviewed with an average age of $50 \pm 11$. Regarding their educational status, $49.4 \%$ of the informants were unschooled while the remaining $50.6 \%$ had attended either primary or secondary school educations Table 1 .

Table 1. Socio-demographic characteristics of the informants in the study area.

\begin{tabular}{llll}
\hline Variables & Name of the Variables & Frequency & Percent (\%) \\
\hline \multirow{4}{*}{ District } & Jabitenan & 28 & 33.7 \\
& Semen Achefer & 30 & 36.1 \\
& Bahir Dar Zuria & 25 & 30.1 \\
& Mankusa-Abdegoma & 9 & 10.8 \\
& Jiga-Yelimodar & 9 & 10.8 \\
& Abasem-Zegay & 10 & 12.0 \\
Kebele & Sankra & 10 & 12.0 \\
& Liben-Dankura & 10 & 12.0 \\
& Yismala-Jankti & 10 & 12.0 \\
& Yigoma-Huletu & 9 & 10.8 \\
& Wenidata & 8 & 9.6 \\
& Gomibat & 8 & 9.6 \\
& Illiterate & 21 & 25.3 \\
Educational & Informal education & 20 & 24.1 \\
Status & $1-4$ & 15 & 18.1 \\
& $5-8$ & 24 & 28.9 \\
& $10-12$ & 3 & 3.6 \\
\hline
\end{tabular}

\subsection{Common Diseases Claimed by Informants}

Informants' claimed, Malaria and Trypanosomiasis was the most troublesome human and animal health problems of the study districts respectively figure 2. However, viral diseases of the humans and foot and mouth diseases of the animal are the least reported health problems in the study districts. According to World Bank report, $61 \%$ of the zone area was exposed to malaria and $30 \%$ to Trypanosomiasis [24].

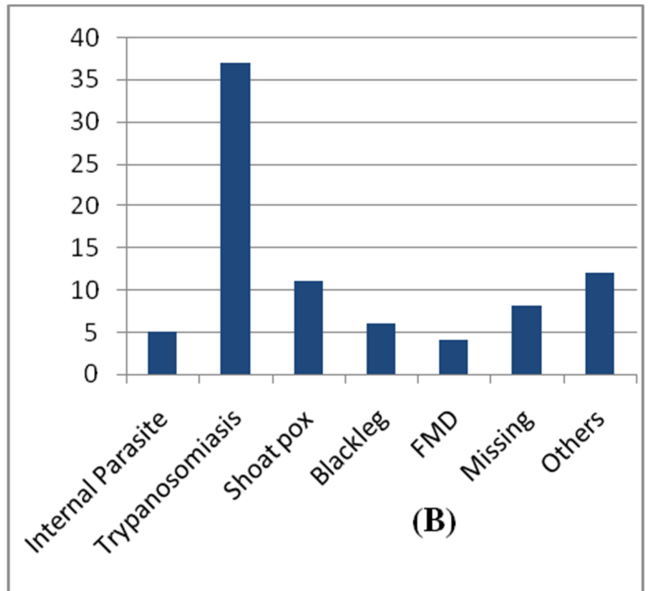

Figure 2. The most common diseases of human (A) and animal (B) in the study area based on informants report.

\subsection{Medicinal Animals and Use-value Reports of Informants}

In this study, a total of 26 animal species were identified and recorded as a source of medicine to treat 33 ailments. Animal-derived medicines of Bos indicus, Trigona spp. and Apis mellifera were frequently reported species to treat various ailments. Moreover, Procavia capensis, Labeobarbus spp. and Hyaenidae carnivora, and other animal-derived medicines were also used to treat different ailments (Table 2 ,). Based on [15] study of 24 animals had been recorded and used as sources of remedies in the Metema district of Gendewuha and Kumeraaftit kebeles as traditional medicine.

Use value report of the 83 informants showed that Bos indicus, Trigona spp., Apis mellifera, Hyaenidae carnivora, and Labeobarbus spp. were the most frequent use-value 
reports $(84 \%, 52 \%, 43 \%, 37 \%$, and $36 \%)$, respectively. However, Tortoise, Spider, and Guinea fowl were the least usevalue report of animal species $(4 \%, 4 \%$, and $2 \%$ ) respectively as shown in Table 2. The higher use-value of animal traditional medicine indicates that particular animal species are used by a large number of people while a lower use value shows that the respondents disagree on the use of that particular animal species for the treatment of ailment [25].

Table 2. Medicinal animal species used by traditional medicine practitioner and its use-value reports of individual animal species based on their relative importance.

\begin{tabular}{|c|c|c|c|c|c|c|}
\hline № & Species Name/Animal taxon & English Name & Local Name & $\sum$ iUVis & $\mathbf{U V}$ & $\% U V$ \\
\hline 1 & Clarias gariepinus & Catfish & Ambaza assa & 4 & 0.05 & 5 \\
\hline 2 & Potamochoerus larvatus & Bush pig & Asama & 10 & 0.12 & 12 \\
\hline 3 & Bos indicus & Cattle & Ykenede Kbite & 70 & 0.84 & 84 \\
\hline 4 & Equus asinus & Donkey & Aheya & 4 & 0.05 & 5 \\
\hline 5 & Gallus domesticus & Chicken & Doro & 14 & 0.17 & 17 \\
\hline 6 & Capra hircus & Goat & Fiyel & 15 & 0.18 & 18 \\
\hline 7 & Hystrix cristata & Porcupine & Jart & 10 & 0.12 & 12 \\
\hline 9 & Phacochoerus africanus & Warthog & Kerkero & 17 & 0.2 & 20 \\
\hline 10 & Phyllophaga spp. & White grub & Qimburs & 5 & 0.06 & 6 \\
\hline 11 & Perdixperdix & Partridge & Qoqe & 10 & 0.12 & 12 \\
\hline 12 & Silvicopra grimmer & Antelope & Midako & 4 & 0.05 & 5 \\
\hline 13 & Panthera pardus & Leopard & Nebir & 4 & 0.05 & 5 \\
\hline 14 & Labeobarbus spp. & White fish & Nechasa & 30 & 0.36 & 36 \\
\hline 15 & Apis mellifera & Honeybee & $\mathrm{Nib}$ & 36 & 0.43 & 43 \\
\hline 17 & Procavia capensis & Wood chuck & Shikoko & 17 & 0.2 & 20 \\
\hline 18 & Trigona spp. & Stingless bee & Tazma Nib & 43 & 0.52 & 52 \\
\hline 19 & Liotrigona spp. & Stingless bee & Tinign & 15 & 0.18 & 18 \\
\hline 20 & Chiroptera spp. & Bat & Yelelitwof & 10 & 0.12 & 12 \\
\hline 21 & Python sebae & Python & Zendo & 9 & 0.11 & 11 \\
\hline 22 & Papio anubis & Baboon & Zinjero & 6 & 0.07 & 7 \\
\hline 23 & Numida meleagris & Guineafowl & Jigra & 2 & 0.02 & 2 \\
\hline 24 & Testudinidae & Tortoise & Eli & 3 & 0.04 & 4 \\
\hline 25 & & Snake & Ebab & 5 & 0.06 & 6 \\
\hline 26 & & Spider & Shererit & 3 & 0.04 & 4 \\
\hline
\end{tabular}

\subsection{Animal Parts to Be Used for Medicinal Purpose by Informants}

A total of 25 animal parts and products were reported by informants to treat 33 types of ailments. Among the total frequency of use report (381) honey and meat took the highest frequency followed by butter (purified butter), milk, liver, fatty meat, and cheese (stored more than 7 years) were described in Figure 3 and some of them were mixed during preparation. Based on [15] animal body parts used as a remedy of human diseases include fat, honey, milk, butter, urine, feces, meat, skin, bones, bile, liver, eggs, horn, etc. and some of these animal medicines need a mix during preparation [16].

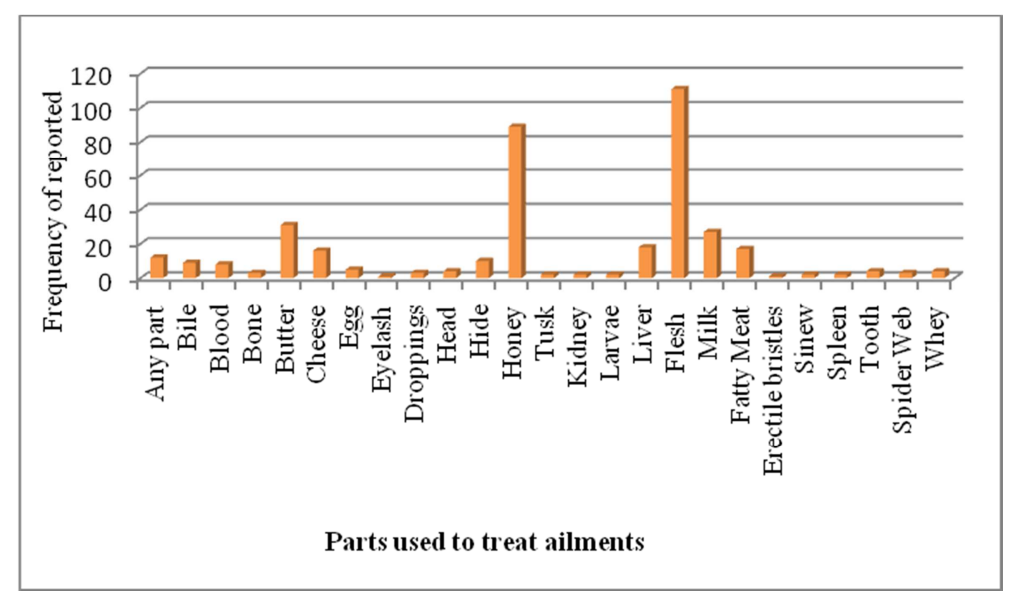

Figure 3. Animal parts and/or products used for the treatment of different ailments.

\subsection{Storage Conditions of Prepared Animal Traditional Medicines}

Most of the informants (77.1\%) stored animal-derived traditional medicines in a clean area, $7.2 \%$ stored in a dry area using glass, and $3.6 \%$ stored in a cold area with or without glass. However, $8.4 \%$ of the informants did not store 
animal-derived traditional medicine. This indicates that the Informants had traditional knowledge of storing animalderived medicine in a clean area. This understood that traditional medicines derived from animals were more perishable than those medicines derived from plants. Therefore, animal-derived traditional medicines need proper sanitation and protection to enhance their shelf life.

\subsection{Informants' Consensus Factor of Ailments Treatment with Animal-Derived Medicines}

Based on the informants' report of remedial action, 12 of the most reported ailments were calculated as an informant consensus factor (ICF). Results showed an average ICF value of $69 \%$. The maximum degree of consensus was developed for the remedy of the evil eye (88\%) followed by dry cough, swelling, and hepatitis $82 \%$ each Table 3. However, Hemorrhoids were the minimum ICF value remedy which is $40 \%$. Informant consensus values below the average ICF value indicate that treatment of a particular ailment was in different animal parts and/or products, which implies heterogeneity of use reports (Table 3 ).

Table 3. ICF value of 12 selected ailments of treatments with animal-derived medicines.

\begin{tabular}{llll}
\hline Disease Category & Nur & Nt & ICF \\
\hline Abdomenal pain & 24 & 8 & 0.70 \\
Asthma & 12 & 5 & 0.64 \\
Dry cough & 40 & 8 & 0.82 \\
Epilepsy & 13 & 7 & 0.50 \\
Hepatitis & 12 & 3 & 0.82 \\
Arthritis & 27 & 8 & 0.73 \\
Malaria & 25 & 8 & 0.71 \\
Rabies & 9 & 3 & 0.75 \\
Swelling & 34 & 7 & 0.82 \\
Wound & 22 & 11 & 0.52 \\
Hemorrhoids & 6 & 4 & 0.40 \\
Evil-eye & 27 & 4 & 0.88 \\
$\sum$ & & & 8.29 \\
ICF value $\left(\sum / 12\right)$ & & & 0.69 \\
\hline
\end{tabular}

\subsection{Fidelity Level and Preferential Ranking of Animal-Derived Medicines to Treat Ailments}

The ethno-zoological uses of animals that are commonly known by the informants have a higher fidelity level (FL) as shown in figure 4 . Use of animal-derived medicine from
Liotrigona spp. used to relive dry-cough tend to have the highest FL (80\%); followed by Labeobarbus spp. for swelling $(33 \%)$ and a product obtained from stingless bees Trigona spp. for dry-cough (30\%).

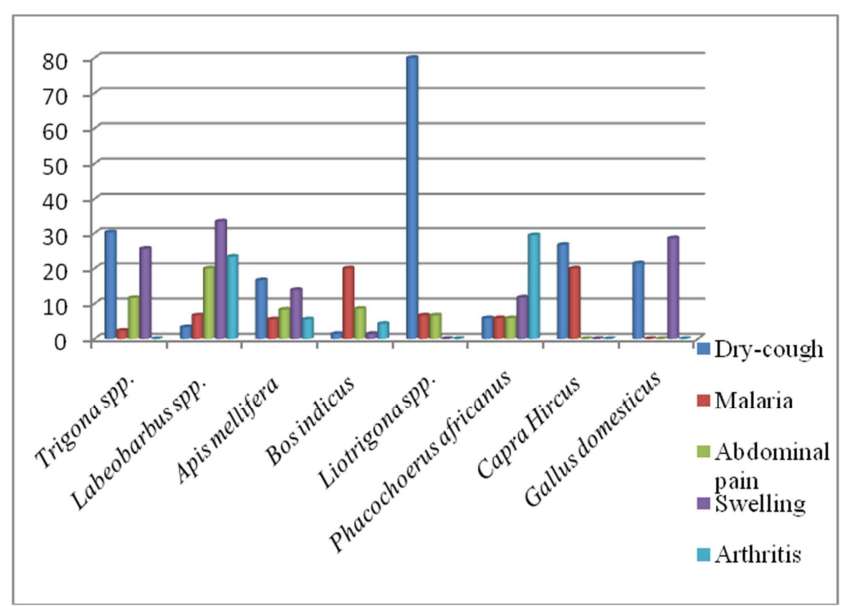

Figure 4. Fidelity level of animal-derived medicines used for treating the selected ailments.

The preferential ranking was conducted to show the preference of one medicinal animal and its parts to the other. This can be conducted when different species are used for the same illness. Based on 18 key informants' reports of 9 animal-derived medicines used to cure malaria, Processed products of Bos indicus (Cheese $\geq 7$ year and Purified Butter $\geq 2$ year) were ranked $1^{\text {st }}$ and $2^{\text {nd }}$ respectively. Therefore, both are used as effective traditional medicine to cure Malaria. Moreover, 'Tazma' honey of Trigona spp., honey of Apis mellifera, 'Tazma' honey of Liotrigona spp., Bile of Capra hircus, the meat of Labeobarbus spp., and meat of Phacochoerus africanus were ranked $3^{\text {rd }}, 4^{\text {th }}, 5^{\text {th }}, 6^{\text {th }}$, $7^{\text {th }}$, and $8^{\text {th }}$ respectively. However, the meat of helmeted guinea fowl (Numida meleagris) was the least preferred animal-derived medicine to cure malaria (Table 4). Moreover, dry Cough was treated with seven animal-derived medicines. Out of these, a chicken egg is the most preferred animal-derived medicine and ranked $1^{\text {st }}$. Larva and honey of honeybees and 'Tazma' honey of Trigona spp. ranked $2^{\text {nd }}$ (Table 5). However, whey of cow milk was the least preferred animal-derived medicine to treat dry Cough.

Table 4. Preferential ranking of 9 animal-derived medicines to treat Malaria based on 18 key informants.

\begin{tabular}{|c|c|c|c|c|c|c|c|c|c|c|c|c|c|c|c|c|c|c|c|c|c|}
\hline Spp. Name & Parts used & R1 & $\mathbf{R 2}$ & R3 & R4 & R5 & R6 & R7 & R8 & R9 & R10 & R11 & R12 & R13 & R14 & R15 & R16 & R17 & R18 & Total & Rank \\
\hline Bos indicus & Cheese $\geq 7$ year & 6 & 4 & 3 & 8 & 9 & 9 & 8 & 9 & 8 & 9 & 5 & 5 & 6 & 7 & 9 & 9 & 9 & 9 & 132 & $1^{\text {st }}$ \\
\hline Apis mellifera & Honey & 8 & 6 & 7 & 7 & 8 & 4 & 2 & 2 & 5 & 6 & 3 & 3 & 4 & 9 & 5 & 8 & 8 & 6 & 101 & $4^{\text {th }}$ \\
\hline Labeobarbus spp. & Meat & 5 & 7 & 4 & 2 & 5 & 2 & 5 & 7 & 6 & 5 & 8 & 8 & 3 & 3 & 3 & 3 & 4 & 2 & 82 & $7^{\text {th }}$ \\
\hline Phacochoerus africanus & Meat & 1 & 2 & 2 & 1 & 3 & 3 & 3 & 5 & 4 & 2 & 7 & 1 & 9 & 1 & 2 & 2 & 1 & 3 & 52 & $8^{\text {th }}$ \\
\hline Capra hircus & Bile & 4 & 3 & 6 & 3 & 6 & 6 & 6 & 4 & 9 & 7 & 2 & 9 & 2 & 5 & 4 & 4 & 6 & 4 & 90 & $6^{\text {th }}$ \\
\hline Liotrigona spp. & Tinign honey & 3 & 1 & 8 & 5 & 1 & 8 & 7 & 8 & 3 & 1 & 4 & 7 & 5 & 6 & 8 & 5 & 5 & 8 & 93 & $5^{\text {th }}$ \\
\hline Trigona spp. & Tazma honey & 7 & 5 & 5 & 6 & 4 & 7 & 4 & 6 & 2 & 3 & 9 & 2 & 7 & 8 & 7 & 7 & 7 & 7 & 103 & $3^{\text {rd }}$ \\
\hline Numida meleagris & Meat & 2 & 8 & 1 & 4 & 2 & 1 & 1 & 1 & 1 & 4 & 1 & 4 & 1 & 4 & 1 & 1 & 2 & 1 & 40 & $9^{\text {th }}$ \\
\hline
\end{tabular}


Table 5. Preferential ranking of 7 animal derived medicines to treat 'Dry Cough' based on 18 key informants.

\begin{tabular}{llllllllllllllllllllllll}
\hline Spp. Name & Used part & R1 & R2 & R3 & R4 & R5 & R6 & R7 & R8 & R9 R10 & R11 & R12 & R13 & R14 & R15 & R16 & R17 & R18 & Total & Rank \\
\hline Gallus domesticus & Egg & 1 & 2 & 7 & 7 & 6 & 1 & 5 & 7 & 6 & 5 & 4 & 3 & 5 & 7 & 7 & 5 & 7 & 5 & 90 & $1^{\text {st }}$ \\
Apis mellifera & Larva \& Honey & 7 & 6 & 3 & 5 & 1 & 5 & 7 & 5 & 4 & 6 & 3 & 6 & 6 & 6 & 4 & 7 & 2 & 4 & 87 & $2^{\text {nd }}$ & \\
Trigona spp. & Tazma honey & 6 & 5 & 5 & 4 & 4 & 6 & 6 & 3 & 2 & 2 & 7 & 5 & 4 & 4 & 5 & 6 & 6 & 7 & 87 & $2^{\text {nd }}$ \\
Liotrigona spp. & Tinign honey & 5 & 1 & 6 & 2 & 3 & 7 & 2 & 4 & 7 & 7 & 6 & 4 & 7 & 2 & 6 & 4 & 3 & 6 & 82 & $4^{\text {th }}$ \\
Capra hircus & Milk & 3 & 3 & 2 & 1 & 7 & 4 & 1 & 2 & 3 & 4 & 2 & 2 & 3 & 5 & 2 & 3 & 5 & 1 & 53 & $6^{\text {th }}$ & \\
Bos indicus & Whey & 2 & 7 & 1 & 6 & 2 & 2 & 4 & 6 & 1 & 1 & 1 & 1 & 1 & 1 & 1 & 1 & 4 & 3 & 45 & $7^{\text {th }}$ \\
Labeobarbus spp. & Meat & 4 & 4 & 4 & 3 & 5 & 3 & 3 & 1 & 5 & 3 & 5 & 7 & 2 & 3 & 3 & 2 & 1 & 2 & 60 & $5^{\text {th }}$ \\
\hline
\end{tabular}

According to key informants' report of eight species of animals derived medicines to treat Arthritis: meat of Phacochoerus africanus, the meat of Labeobarbus spp. and meat of Potamochoerus larvatus ranked $1^{\text {st }}, 2^{\text {nd }}$, and $3^{\text {rd }}$ respectively. However, the meat of Procavia capensis was the least preferred animal-derived medicine to treat Arthritis as shown in Table 6.

Table 6. Preferential ranking of 8 animal-derived medicines to treat Arthritis based on 18 key informants.

\begin{tabular}{|c|c|c|c|c|c|c|c|c|}
\hline Respondents & $\begin{array}{l}\text { Apis } \\
\text { Mellifera } \\
\end{array}$ & $\begin{array}{l}\text { Phacochoerusa } \\
\text { fricanus }\end{array}$ & $\begin{array}{l}\text { Labeobarbus } \\
\text { spp. }\end{array}$ & $\begin{array}{l}\text { Potamochoerus } \\
\text { larvatus }\end{array}$ & $\begin{array}{l}\text { Hystrix } \\
\text { cristata }\end{array}$ & $\begin{array}{l}\text { Bos } \\
\text { indicus }\end{array}$ & $\begin{array}{l}\text { Clarias } \\
\text { gariepinus }\end{array}$ & $\begin{array}{l}\text { Procavia } \\
\text { capensis }\end{array}$ \\
\hline $\mathrm{R} 1$ & 4 & 5 & 8 & 6 & 2 & 3 & 7 & 1 \\
\hline $\mathrm{R} 2$ & 6 & 3 & 7 & 4 & 2 & 5 & 8 & 1 \\
\hline R3 & 8 & 1 & 7 & 4 & 2 & 5 & 6 & 3 \\
\hline R4 & 5 & 8 & 4 & 6 & 2 & 1 & 7 & 3 \\
\hline R5 & 2 & 8 & 6 & 3 & 4 & 1 & 7 & 5 \\
\hline R6 & 5 & 8 & 7 & 6 & 2 & 1 & 3 & 4 \\
\hline R7 & 1 & 8 & 7 & 6 & 4 & 2 & 5 & 3 \\
\hline R8 & 1 & 8 & 7 & 6 & 5 & 2 & 3 & 4 \\
\hline R8 & 6 & 8 & 7 & 5 & 1 & 4 & 3 & 2 \\
\hline R9 & 3 & 8 & 2 & 5 & 1 & 4 & 7 & 6 \\
\hline $\mathrm{R} 10$ & 4 & 8 & 5 & 7 & 2 & 3 & 6 & 1 \\
\hline $\mathrm{R} 12$ & 5 & 7 & 8 & 6 & 3 & 1 & 2 & 4 \\
\hline R13 & 5 & 6 & 8 & 7 & 4 & 1 & 2 & 3 \\
\hline $\mathrm{R} 14$ & 6 & 5 & 4 & 8 & 7 & 3 & 1 & 2 \\
\hline $\mathrm{R} 15$ & 8 & 5 & 1 & 6 & 7 & 3 & 2 & 4 \\
\hline R16 & 8 & 6 & 5 & 4 & 3 & 7 & 2 & 1 \\
\hline R17 & 4 & 8 & 2 & 6 & 7 & 3 & 1 & 5 \\
\hline R18 & 6 & 8 & 5 & 2 & 3 & 7 & 4 & 1 \\
\hline Total & 87 & 118 & 100 & 97 & 61 & 56 & 76 & 53 \\
\hline Rank & 4 th & $1 \mathrm{st}$ & $2^{\text {nd }}$ & $3 \mathrm{rd}$ & 6th & 7 th & 5 th & 8th \\
\hline
\end{tabular}

\subsection{Paired Comparison of Animal-derived Medicines for the Treatment of Ailments}

Paired comparison of 6 medicinal animal species was used to indicate the efficacy and popularity of animal-derived medicines to treat malaria as shown in Table 7. The result of paired comparisons revealed that purified butter $\geq 2$ years, Cheese $\geq 7$ years, 'Yetinign Tazma' honey of Lio trigona spp., and 'Tazma honey' of Trigona spp. were the most popular and efficacious animal-derived medicines to cure malaria and ranked $1^{\text {st }}, 2^{\text {nd }}, 3^{\text {rd }}$, and $4^{\text {th }}$ respectively. However, the bile of goat (Capra hircus) and meat of white fish (Labeobarbus spp) was the least popular and efficacious animals to cure malaria.

Table 7. A paired comparison of 6 animal-derived medicines for the treatment of Malaria based on 18 key informants.

\begin{tabular}{|c|c|c|c|c|c|c|}
\hline Respondents & $\begin{array}{l}\text { Bos indicus (Cheese } \geq \\
\text { 7year) }\end{array}$ & $\begin{array}{l}\text { Capra hircus } \\
\text { (Bile) }\end{array}$ & $\begin{array}{l}\text { Liotrigona spp. } \\
\text { (Yetenegn Tazma) }\end{array}$ & $\begin{array}{l}\text { Bos indicus (Purified } \\
\text { Butter } \geq 2 \text { year) }\end{array}$ & $\begin{array}{l}\text { Trigona spp. } \\
\text { (Tazma honey) }\end{array}$ & $\begin{array}{l}\text { Labeobarbus } \\
\text { spp.(Meat) }\end{array}$ \\
\hline R1 & 1 & 2 & 4 & 5 & 3 & 0 \\
\hline $\mathrm{R} 2$ & 2 & 3 & 1 & 4 & 5 & 0 \\
\hline R4 & 3 & 3 & 0 & 5 & 2 & 2 \\
\hline R5 & 3 & 4 & 0 & 5 & 2 & 1 \\
\hline R6 & 2 & 2 & 4 & 5 & 2 & 0 \\
\hline R8 & 1 & 4 & 2 & 2 & 4 & 2 \\
\hline R8 & 4 & 5 & 2 & 3 & 0 & 1 \\
\hline R9 & 3 & 1 & 0 & 5 & 2 & 4 \\
\hline $\mathrm{R} 10$ & 3 & 0 & 3 & 5 & 3 & 1 \\
\hline $\mathrm{R} 12$ & 1 & 5 & 2 & 3 & 0 & 4 \\
\hline $\mathrm{R} 13$ & 3 & 1 & 4 & 5 & 0 & 2 \\
\hline $\mathrm{R} 14$ & 3 & 1 & 4 & 0 & 5 & 2 \\
\hline R15 & 4 & 0 & 3 & 2 & 5 & 1 \\
\hline
\end{tabular}




\begin{tabular}{lllllll}
\hline Respondents & $\begin{array}{l}\text { Bos indicus (Cheese } \geq \\
\text { 7year) }\end{array}$ & $\begin{array}{l}\text { Capra hircus } \\
\text { (Bile) }\end{array}$ & $\begin{array}{l}\text { Liotrigona spp. } \\
\text { (Yetenegn Tazma) }\end{array}$ & $\begin{array}{l}\text { Bos indicus (Purified } \\
\text { Butter } \geq 2 \text { year) }\end{array}$ & $\begin{array}{l}\text { Trigona spp. } \\
\text { (Tazma honey) }\end{array}$ & $\begin{array}{l}\text { Labeobarbus } \\
\text { spp.(Meat) }\end{array}$ \\
\hline R16 & 5 & 0 & 4 & 1 & 3 & 2 \\
R17 & 5 & 4 & 2 & 1 & 3 & 0 \\
R18 & 7 & 2 & 3 & 1 & 2 & 0 \\
Total & 56 & 38 & 44 & 62 & 43 & 27 \\
Rank & 2nd & 5 th & $3^{\text {rd }}$ & $1^{\text {st }}$ & 4 th & 6 th \\
\hline
\end{tabular}

\subsection{Informants Attitude on the Conservation Aspects of Animal Traditional Medicine}

More than half of the informants (61.4\%) reported the current status of medicinal animals' as rare to obtain them and $38.6 \%$ of them perceived their status in a declining state. The informants also reported the demand for seeking medicinal animals to treat ailments as rare $(74.7 \%)$, increasing (20.5\%), and decreasing (4.8\%). Informants listed some of the threats that caused the decline of medicinal animals such as deforestation, hunting, climate change, agricultural expansion and shortage of forage, overexploitation of animal genetic resources, lack of modern medication, lack of shelter, and lack of awareness. Based on the Millennium Ecosystem Assessment report extinction, overhunting, habitat loss/degradation/ fragmentation, invasion of non-native species, pollution, and climate change as main threats of global biodiversity [26]. There is a massive loss of wildlife across the globe due to over-hunting [27]. Therefore, informants practiced different techniques to conserve medicinal animals. For instance, $80.7 \%$ conserve animal traditional medicine by protecting the forests which are shelters of medicinal animals. Moreover, prevention of hunting, application of breeding, and raising awareness of the local people about medicinal animals be also practiced to conserve medicinal animals.

Informants reported modernization harmed the application and use of animal-derived traditional medicine. Because experts abuse traditional healers as well as users to ban preparation and use of animal-derived traditional medicine and they consider it as folk medicine. Thus, modernization made local peoples forget the knowledge of animal-derived medicine. As [17] noted knowledge of traditional healing practices using animals is fast disappearing due to modernization. This showed that the loss of traditional knowledge has much impact on the development of modern medicine [14].

\subsection{Inheritance of Healing Wisdom}

Informants who practice Animal-derived traditional medicine to treat ailments inherited the traditional knowledge from their parents, particularly fathers $(47 \%)$, mothers $(14.5 \%)$, and grandfathers, grandmothers, and brothers $(10.8 \%)$. Moreover, $12 \%$ of the informants inherited the animal traditional knowledge from friends, community neighbors, monks, and nephews. However, $15.7 \%$ of the informants did not want to reveal the sources of their knowledge of animal-derived traditional medicine. Informants (94\%) showed a willingness to inherit the knowledge of animal traditional medicine to their daughters $(56.6 \%)$, sons $(12 \%)$, families $(8.4 \%)$, friends $(2.4 \%)$, and researchers $(1.2 \%)$. Besides, $13.3 \%$ of the informants showed a willingness to inherit the knowledge of animal-derived traditional medicine to any interested person. However, $6 \%$ of the informants did not want to inherit the traditional knowledge of medicinal animals to any person. Traditional healers in Ethiopia held their indigenous knowledge in secret [19] and showed interest to pass on the animal-derived traditional medicinal knowledge orally only to their eldest son, at their old age [28].

The attitude of urban inhabitants towards the use of traditional medicine

A total of 57 individuals $(73.3 \%$ males and $26.3 \%$ females) of urban dwellers were interviewed to assess the use of traditional medicine derived from animals, of which, $43.9 \%$ were district Livestock and Fishery expertise including animal health experts, $29.8 \%$ are extension agents and $26.3 \%$ were district health expertise and officers.

Out of the total traditional medicine users of urban inhabitants, $56.1 \%$ used traditional medicine for treating ailments. However, $43.9 \%$ did not use traditional medicine for treating ailments. The reason for not using traditional medicines for treating ailments was the unknown dose of medicine used for treatment, doubts about the safety of the treatment, and efficacy of traditional medicine. Moreover, the non-apparent use, availability and accessibility of the traditional medicine to one's dwelling place limit the preference of using them as traditional medicine.

Users of urban inhabitants (42.1\%) used traditional medicine derived from both plants and animals, (12.3\%) from plants only, and (1.8\%) from animals only. The reason for using much more traditional medicines derived from plants than animals was since most of the world's modern medicines are mostly derived from plants, and science affirmed their efficacy in laboratories. Besides, plant-derived traditional medicines were easily accessible and had a lower price than modern medicines, and easily available. Users of animal-derived traditional medicine reasoned that animal remedies were natural, harmless, fast to treat, used as an ingredient in combination with other plant medicines and some of them are available on markets such as honey, butter, fish, milk, egg, liver, and Tazma honey. $26.3 \%$ of urban user inhabitants reported traditional animal medicines were sold for treating ailments such as evil eye, hepatitis, asthma, wound, and sexual disorders.

The knowledge of Zoonotic diseases was assessed in urban inhabitant users of animal-derived traditional medicine. Users $84 \%$ knew and listed Zoonotic diseases such as Rabies, Brucellosis, Tuberculosis, Anthrax, and Blackleg. This 
indicates urban inhabitants were more educated than rural ones. However, $16 \%$ of them did not know about Zoonotic diseases. Urban inhabitant users described major challenges on the use of animal-derived traditional medicine as follows: $22.8 \%$ described the challenge as a shortage of supply, $17.5 \%$ declared as lack of knowledge, $10.5 \%$ reported sanitation problems, and others listed the challenge as the dose of animal-derived medicine used for treatment is an unknown and religious restriction on some of the animal-derived traditional medicine. Moreover, the lack of scientific research and the decline of traditional healers were stated as the main challenges by some of the users. Among the challenges, a shortage of supply is due to over hunting of animals, deforestation, and climate change.

\section{Conclusion and Recommendation}

Ethiopia is rich in biological resources and home to different ethnic groups, many of which have adopted various techniques to protect their health care systems and uses traditional medicine derived from plants and animals. Animal-derived medicines are an alternative to treat ailments in rural areas. Thus, the results of this study revealed 25 parts and/or products of 26 animal species were used as traditional medicine to treat 33 ailments in the study area. Moreover, this study recorded the most popular animal-derived medicine to cure various ailments. However, the status of medicinal animals and the demand of seeking medicinal animals were rare due to different factors. Besides urban dwellers of government employees were recorded as users of animal-derived traditional medicine.

The following recommendations are drawn from the study

a) The government must strengthen traditional healers with training, club formation, material and financial support, and improve means of protecting their intellectual property rights. Moreover, continual awareness-raising and training should be given to the community of the study area to avoid egocentric and abusive behavior and to enhance the participatory role of the local people regard to issues of traditional medicinal knowledge.

b) Researchers such as chemists and pharmacists should undergo a detailed study to identify which chemical constituent of animal and animal products is responsible for the respective treatment of ailments in the study area.

\section{Conflict of Interest Statement}

The authors declare no conflict of interest.

\section{Acknowledgements}

We greatly thank to Ethiopian Biodiversity Institute, Genetic Resource Access and Benefit Sharing Directorate for the financial support for data collection. Our thanks also went to the study zone, district, and kebeles expertise. The local community specifically traditional healers is also likely appreciated.

\section{References}

[1] Boakye, M. K., Pietersen, D. W., Kotzé, A., Dalton, D. L., and Jansen, R. (2015). Knowledge and Uses of African Pangolins as a Source of Traditional Medicine in Ghana. PLoS ONE; 10 (1): e0117199.

[2] Keter, L. K., and Mutiso, P. C. (2012). Ethnobotanical studies of medicinal plants used by Traditional Health Practitioners in the management of diabetes in Lower Eastern Province, Kenya. Journal of Ethnopharmacology; 139: 74-80.

[3] Endashaw Bekele (2007). Study on Actual Situation of Medicinal Plants in Ethiopia. Japan Association for International Collaboration of Agriculture and Forestry (JAICAF); 1-76.

[4] Soewu, D. A. and Adekanola, T. A. (2011). Traditionalmedical knowledge and perception of pangolins (Manissps) among the Awori people, Southwestern Nigeria. J. Ethnobiol. Ethnomed; 7 (25): 1-11.

[5] Attisso, M. A. (1983). Phyto pharmacology. In: Traditional Medicine and Health care Coverage (Bannerman, R. H., Burton, J., and Wen-Chieh, C., eds.). World Health Organization, Geneva pp. 194-206.

[6] Lohani, U., Rajbhandari, K. and Shakuntala, K. (2008). Need for systematic ethno-zoological studies in the conservation of ancient knowledge system of Nepal. A Review Indian Journal of Traditional Knowledge; 7 (4): 634-637.

[7] Costa-Neto, E. M. (2005). Animal-based medicines: Biological prospection and the sustainable use of zootherapeutic resources. Ann. Acad. Bras. Cienc; 77 (1): 3343.

[8] Lev, E. (2003). Traditional healing with animals (zootherapy): Medieval to present-day Levantine practice. J. Ethno pharmacol; 86: 107-118.

[9] Adeola, M. O. (1992). Importance of wild Animals and their parts in the culture, religious festivals, and traditional medicine, of Nigeria. Environmental Conservation; 19 (2): $125-134$.

[10] Anageletti, L. R., Agrimi, U., Curia, C., French, D., and Mariani-Costantini, R. (1992). Healing rituals and sacred serpents. Lancet; 340: 223-225.

[11] Albuquerque, U. P., Edwin, L., Cooper, E. L., Medeiros, M. F., Alves, R. R. and Ladio A. H. (2012). Medical Ethnobiology and Ethnopharmacology in Latin America.

[12] Alves, RRN. (2011). The faunal drugstore: Animal-based remedies used in traditional medicines in 'Latin America. Journal of Ethnobiology and Ethnomedicine; 7: 9.

[13] Gelahun Abate (1989). Etse-debdabe. (Ethiopian Traditional Medicine). Biology Department Science Faculty, Addis Ababa University.

[14] Gidey Yirga, Mekonen Teferi and Yemane Gebreslassea (2011). Ethno-zoological study of traditional medicinal animals used by the people of Kafta-Humera District, Northern Ethiopia. International Journal of Medicine and Medical Sciences; 3 (10): 316-320. 
[15] Mezgebu Belay (2015). Medicinal Use of Fauna in the Indigenous Medicine System of Gendewuha and Kumeraaftit Kebeles of MetemaWoreda, North West Ethiopia; International Journal of Innovative Research and Development; 4 (8): 459-464.

[16] Dereje W. Yohannes and Meseret Chane (2014). Ethnozoological study of Traditional Medicinal Animals used by the Kore People in AmaroWoreda, Southern Ethiopia; International Journal of Molecular Evolution and Biodiversity; 4 (2): $1-9$

[17] Jain, A., Katewa, S. S., Galav, P. K. andNag, A. (2007). Unrecorded Ethnomedicinal Uses of Biodiversity from Tadgarh-Raoli Wildlife Sanctuary, Rajasthan, India. Acta Botanica Yunnanica; 29: 337-344.

[18] Alves, R. R. N., and Rosa, I. L. (2005). Why study the use of animal products in traditional medicines? J. Ethno biol.; 1: 15 .

[19] Samuel Zerabruk and Gidey Yirga (2012). Traditional knowledge of medicinal plants in Gindeberet district, Western Ethiopia. South Afr. J. Bot.; 78: 165-169.

[20] Habtemariam Assefa, Aklilu Bogale, Berhanu Gebremedhin, Zeleke Mekuriaw, Teshome Derso, Yigzaw Dessalegn, AzageTegegne and Dirk Hoekstra (2016). Village Chicken Production and Marketing in West Gojjam Zone, Ethiopia. Current Research in Agricultural Sciences; 3 (4): 64-73.

[21] Central Statistics Authority of Ethiopia (2007). Summary and Statistical Report of the 2007 Population and Housing Census, Central StatesticAutority of Ethiopia, Addis Ababa, Ethiopia.
[22] Senedu Bekele Gebreegziabher, Solomon Abebe Yimer and Bjune, G. A. (2016). Tuberculosis Case Notification and Treatment Outcomes in West Gojjam Zone, Northwest Ethiopia: A Five-Year Retrospective Study. Amhara Regional State Health Bureau, Bahir Dar, Ethiopia. Journal of Tuberculosis Research; 4: 23-33.

[23] Tilahun Gebey and Zeleke Mekuriaw (2013). Diagnosis and intervention plans for West Gojjam Zone, Amhara Region. Livestock and Irrigation Value Chains for Ethiopian Smallholder; pp. 9.

[24] World Bank (2004). A Regional Characterization Assessing Ethiopia's Growth Potential and Development Obstacles. Country Economic Memorandum, Ethiopian Report; pp. 18.

[25] Vats, R. and Thomas, S. (2015). A study on use of animals as traditional medicine by Sukuma Tribe of Busega District in North-western Tanzania. Journal of Ethnobiology and Ethnomedicine; 11: 38 .

[26] Millennium Ecosystem Assessment (2005). Ecosystems and Human Well-being: Biodiversity Synthesis. World Resources Institute, Washington, DC.

[27] Bennett, E. L., Milner-Gull and, E. J., Bakarr, M., Eves, H. E., Robinson, J. G. and Wilkie, D. S (2002). Hunting the world's wildlife to extinction Oryx; 36: 328-329.

[28] Jansen, P. C. M. (1981). Spices, Condiments and Medicinal Plants in Ethiopia: Their Taxonomy and Agricultural Significance. College of Agriculture, Addis Ababa University, Ethiopia and the Agricultural University, Wageningen, the Netherlands, Centre for Agricultural Publishing and Documentation, Wageningen. 